\title{
Bir devlet hastanesi acil servisinde kırık tanısı alan hastaların değerlendirilmesi
}

\section{Evaluation of patients diagnosed with fracture in an emergency department of a public hospital}

\author{
Çağdaş PAMUK* \\ Medical Park Silivri Hastanesi, Ortopedi ve Travmatoloji Kliniği, İstanbul/TÜRKiYE
}

Öz

Amaç: Kırık olguları günümüzde aktif yaşamın artmasıyla birlikte giderek artış göstermektedir. Bu çalışmada Kars Harakani Devlet Hastanesinde kırık tanısı almış hastaların, demografik özelliklerini ve nasıl tedavi edildiklerini değerlendirmeyi amaçladık.

Gereç ve Yöntemler: Veriler Haziran2016-Kasım 2018 tarihleri arasında Kars Harakani Devlet Hastanesi kayıt sisteminden retrospektif olarak elde edildi. Hastaların yaş, cinsiyet, travmanın şekli, tanısı ve hastaya uygulanan tedaviler tespit edildi. Tüm veriler SPSS version 13 programında analiz edildi.

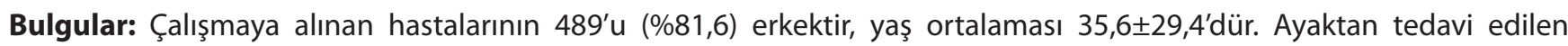
hastaların \%12,8'ine nöbetçi acil uzmanı müdahale etmiştir. Yatış yapılan 469 hastanın yatııılığı servise göre dağılımı incelendiğinde 337'si $(\% 71,8)$ ortopedi servisine yatıııımıştır. Ortopedi yatışı yapılan hastaların \%11,3'ünü (n:53) radiusulna kırıkları oluşturmaktadır. Ortopedi servisine yatırılan hastaların 272 'sine $(\% 80,7)$ cerrahi tedavi, $65^{\prime}$ ine $(\% 19,2)$ konservatif tedavi uygulanmıştır.

Sonuç: Sonuç olarak acil serviste kırık tanısı alan hastaların önemli bir kısmının, ortopedi kliniği tarafından değerlendirildiği ve önemli bir kısmının güncel ortopedik literatüre göre cerrahi olarak tedavi edildiği akılda tutulmalıdır.

Anahtar kelimeler: kırık tedavisi; acil servis; ortopedi 


\begin{abstract}
Aim: Fracture cases are increasing with active life. In this study, we aimed to evaluate the demographic characteristics and treatment of patients diagnosed with fracture in Kars Harakani State Hospital.
\end{abstract}

Material and Methods: The data were retrospectively obtained from the registration system of Kars Harakani State Hospital between June2016 and November 2018. Age, gender, type of trauma, diagnosis and treatment of the patients were determined. All data were analyzed in SPSS version 13 program.

Results: 489 (81.6\%) of the patients were male and the mean age was $35.6 \pm 29.4 .12 .8 \%$ of the outpatients were treated by emergency medicine specialist. When the distribution of 469 patients according to the service was evaluated, 337 (71.8\%) were hospitalized in the orthopedics service. $11.3 \%$ (n: 53 ) of the patients who underwent orthopedics constitute the radius-ulna fractures. Surgical treatment was applied to $272(80.7 \%)$ patients and conservative treatment was applied to 65 (19.2\%) patients.

Conclusion: As a result, it should be kept in mind that a significant proportion of the patients diagnosed with fracture in the emergency department are evaluated by the orthopedics clinic and that a significant proportion of them are treated surgically according to the current orthopedic literature.

Keywords: fracture treatment; emergency room; orthopaedics

\section{Giriş}

Kırık olguları günümüzde aktif ve sosyal yaşamın artmasıyla birlikte artış göstermektedir[1,2] Sosyal hayatta insanlar çeşitli düşük ya da yüksek enerjili travmalara maruz kalmakta ve bunların bir kısmında çeşitli vücut bölgelerinde kırıklar oluşabilmektedir.[3-5]

Trafik kazaları gibi yüksek enerjili travmalar yüksek oranda hayati tehlike ve kalıcı sakatlık bırakabilecek kırıkların oluşmasına neden olabilirken, basit düşmeler sonucu oluşan kırıklarda hayati tehlike olasılığı düşmekle birlikte fonksiyon ve iş gücü kaybına neden olabilmektedir.[6-8]

Kırık hastalarının ilk değerlendirmesinin yapıldığı bölüm olan acil servislerde hastaların bir bütün olarak değerlendirilip ilgili bölümler tarafından gerekli konsültasyonlarının yapılması, en az fonksiyon ve iş gücü kaybı ile hastaların tedavi edilmesi açısından önem taşımaktadır[9,10]

$\mathrm{Bu}$ araştırmada acil serviste kırık tanısı alan hastaların, demografik özelliklerinin, yaralanma mekanizmalarının ve hangi bölümler tarafından nasıl tedavi edildiklerinin değerlendirilmesi amaçlandı.

\section{Gereç ve Yöntemler:}

Haziran 2016-Kasım 2018 tarihleriarasında acil servise başvuran ve kırık tanısı alan hastalar retrospektif olarak değerlendirildi. Çalışma için Kars Harakani Devlet Hastanesi yönetiminden izin alındı. Bu çalışma Helsinki IIlkeler Deklarasyonuna uygun olarak hazırlanmıştır. Çalışmanın verileri acil servis ve ortopedi servis kayıtları üzerinden toplandı. Hastalardan imzalı aydınlanmış onam formları alındı. Hastaların demografik özellikleri (yaş, cinsiyet), travmanın şekli, hastanın tanısı, hastaya uygulanan tedaviler, tedavilerin ayaktan ya da yatarak olması, ayaktan hastaların tedavilerinin acil uzmanı tarafından ya da ortopedi uzmanı tarafından uygulanması, yatan hastaların hangi bölümler tarafından yatırıldığı, operasyon oranları, operasyon çeşitleri ve yatış süreleri kaydedildi. Kayıtlar MS Excell programı kullanılarak kaydedildi ve istatistiksel analizler "SPSS version 13" paket programı kullanılarak yapıldı. Veriler ortalama \pm standart hata ve frekans $(n, \%)$ olarak sunulmuştur. İstatistiksel metot olarak iki ortalama arasındaki farkın önemlilik testi kullanılmıştır. Veriler tablolarda birey sayısı, \%'si şeklinde belirtilip \% dağılımları verilmiştir. Tüm istatistiksel analizlerde anlamlılık düzeyi $\mathrm{p}<0,05$ olarak kabul edilmiştir.

\section{Bulgular}

Kars Harakani Devlet Hastanesi acil servisinde Haziran2016Kasım 2018 tarihleri arasında kırık tanısı almış hasta sayısı 599'dur. Kırık hastalarının 489'u $(\% 81,6)$ erkek 110' u $(\% 18,3)$ kadındır. Erkek olgular istatistiksel olarak anlamlı derecede çoğunluktadır $(p<0.05)$. Çalışmaya alından hastaların yaş ortalaması $35,6 \pm 29,4^{\prime}$ dür. Acil serviste kırık tanısı almış hastaların 130'u $(\% 21,7)$ ayaktan tedavi almış, 469'u $(\% 78,2)$ yatırılarak tedavi edilmiştir. Ayaktan tedavi edilen hastaların \%12,8'ine nöbetçi acil uzmanı müdahale etmiş olup, \%87,2'sine diğer branş uzmanları icabet ederek müdahale etmiştir. Diğer branş hekimleri tarafından yapılan müdahale istatistiksel anlamlı oranda fazladır $(p<0,05)$

Yatış yapılan 469 hastanın yatırıldığı servise göre dağılımı Tablo 1.'de gösterilmiştir. Bu hastaların 337'si $(\% 71,8)$ ortopedi servisine, 99'u $(\% 21,1)$ beyin cerrahisi servisine, 12'si $(\% 2,5)$ plastik cerrahi servisine, 9'u (\%1,9) kulak burun boğaz servisine, 6'sı $(\% 1,2)$ çocuk cerrahisi servisine, 6'sı $(\% 1,2)$ genel cerrahi servisine yatırılmıştır. Kırık hastalarının ortopedi servine yatırılma oranları istatistiksel anlamlı oranda fazladır $(p<0,05)$. 


\begin{tabular}{|c|c|c|c|c|c|c|c|}
\hline & Ortopedi & Beyin Cerrahisi & Plastik Cerrahi & Kulak Burun Boğaz & Çocuk Cerrahisi & Genel Cerrahi & Toplam \\
\hline Sayı & 337 & 99 & 12 & 9 & 6 & 6 & 469 \\
\hline$\%$ & 71,8 & 21,1 & 2,5 & 1,9 & 1,2 & 1,2 & 100 \\
\hline
\end{tabular}

Kırık tanısı alan hastaların, kırığın oluş şekline göre dağılımı Tablo 2. de gösterilmiştir. Buna göre \%48,9 (n:293) ile en fazla oranı düşme sonucu oluşan kırıklar oluşturmaktadır. Bunu $\% 25,8$ (n:155) ile trafik kazaları takip etmektedir.

\begin{tabular}{lcc}
\multicolumn{3}{|c}{ Tablo 2. Kırığın oluş şekline göre hastaların dağılımı } \\
\cline { 2 - 3 } & Sayı & $\%$ \\
\hline Düşme & 293 & 48,9 \\
\hline Trafik Kazası & 155 & 25,8 \\
\hline Spor Yaralanması & 46 & 7,6 \\
\hline İş kazası & 43 & 7,1 \\
\hline Ağrılık Altında Kalma & 34 & 5,6 \\
\hline Darp & 16 & 2,6 \\
\hline Ateşli Silah Yaralanması & 12 & 2,0 \\
\hline Toplam & 599 & 100
\end{tabular}

Kırık hastalarının en yüksek oranda yatırıldığı servis olan ortopedi servisine yatırılan hastaların ortopedik tanıları ve bu tanıların \% dağılımları Tablo 3.'te gösterilmiştir. Buna göre \%11,3 (n:53) oranla radius-ulna kırıkları en yüksek orana sahiptir. Kırıkların tanılarının dağılımı açısından anlamlı bir farklılık yoktur $(p>0,05)$.

Ortopedi servisine yatırılan hastaların 272 'sine $(\% 80,7)$ cerrahi tedavi, 65'ine $(\% 19,2)$ konservatif tedavi uygulanmıştır $(p<0.05)$. Ortopedi servisinde cerrahi tedavi uygulanan hastalara uygulanan cerrahinin çeşitleri Tablo 4.'te gösterilmiş olup \%58,8 (n:160) oranla açık redüksiyon internal fiksasyon (ARIF) operasyonu en yüksek oranda uygulanan operasyondur $(p<0,05)$. Konservatif tedavi uygulan hastalara uygulanan

\begin{tabular}{|c|c|c|}
\hline & Sayı & $\%$ \\
\hline Radius-Ulna & 53 & 11,3 \\
\hline Fibula & 31 & 9,1 \\
\hline Humerus alt uç & 31 & 9,1 \\
\hline Femur proksimal uç & 22 & 6,5 \\
\hline Tibia alt uç & 21 & 6,2 \\
\hline Falangeal & 21 & 6,2 \\
\hline Metatarsal & 19 & 5,6 \\
\hline Femur diafiz & 17 & 5,0 \\
\hline Tibia proksimal uç & 17 & 5,0 \\
\hline Humerus proksimal uç & 16 & 4,7 \\
\hline Tibia diafiz & 15 & 4,4 \\
\hline Metakarpal & 12 & 3,5 \\
\hline Humerus diafiz & 11 & 3,2 \\
\hline Karpal & 9 & 2,6 \\
\hline Femur distal uç & 8 & 2,3 \\
\hline Klavikula & 8 & 2,3 \\
\hline Tarsal & 7 & 2,0 \\
\hline Skapula & 6 & 1,7 \\
\hline Pelvis & 6 & 1,7 \\
\hline Asetabulum & 4 & 1,1 \\
\hline Vertebra & 3 & 0,8 \\
\hline Toplam & 337 & 100 \\
\hline
\end{tabular}

tedavi Tablo 5.'te gösterilmiştir. \%50,7 ile en yüksek oranla kapalı redüksiyon uygulanmıştır $(p<0,05)$.

Ortopedi servisine yatırılan 337 hastanın ortalama yatış süresi $10,3 \pm 8,1^{\prime}$ dir. Konservatif tedavi alanlar 5,8 03,1 gün, cerrahi

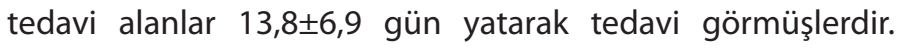
Konservatif tedavi alanlar ile cerrahi tedavi alanlar karşılaştırıldığında farklılık anlamlıdır $(p<0,05)$.

\begin{tabular}{|c|c|c|c|c|c|c|c|}
\hline & $\begin{array}{l}\text { Açık redüksiyon internal } \\
\text { fiksasyon }\end{array}$ & $\begin{array}{l}\text { Kapalı redükisyon } \\
\text { internal fiksasyon }\end{array}$ & Artroplasti & $\begin{array}{l}\text { Eksternal } \\
\text { fiksasyon }\end{array}$ & Ampütasyon & Diğer & Toplam \\
\hline Sayı & 160 & 42 & 11 & 15 & 1 & 43 & 272 \\
\hline$\%$ & 58,8 & 15,4 & 4,0 & 5,5 & 0,3 & 15,8 & 100 \\
\hline
\end{tabular}

\begin{tabular}{|c|c|c|c|c|c|c|}
\hline & Kapalı redüksiyon & Traksiyon & Korse & Hemogram takibi & Diğer & Toplam \\
\hline Sayı & 33 & 4 & 3 & 8 & 17 & 65 \\
\hline$\%$ & 50,7 & 6,1 & 4,6 & 12,3 & 26,1 & 100 \\
\hline
\end{tabular}




\section{Tartışma}

Çalışmamızın kısıtıılıkları retrospektif olması ve verilerin tamamının elektronik sistemden değil, bir kısmının basılı dosya sisteminden elde edilmiş olmasıdır.

Daha önceki çalışmalarda bildirildiği gibi travma olgularında erkek hastaların daha yüksek bir oranı oluşturduğu bildirilmiştir[11,12]. Bizim çalışmamızda da literatürle uyumlu olarak kırık olgularında \%81,6 oranla erkek hastalar çoğunluğu oluşturmaktadır. Çalışmamızın yapıldığı aynı hastanedeyapılan başka bir çalışmada geriatrik popülasyonda acil servisden ortopedi servisine yapılan yatışlarda kadın hastaların daha fazla olduğu bildirilmiştir[13]. Ancak bu çalışmada geriatrik popülasyon değerlendirmeye alınmış olup tüm yaş grupları incelendiğinde erkek hastaların çoğunluğu oluşturduğu görülmektedir.

Çalışmamızda değerlendirilen hastaların yaş ortalaması 35,6 $\pm 29,4$ 'tür. Travma maruziyeti ve buna bağlı kırık oluşmasının daha çok aktif yaşam ve aktif yaşam beklentisi olan yaş gruplarında görüleceği düşüncesindeyiz. Daha önceki çalışmalarda da bu bulgu desteklenmektedir[14,15].

Kars Devlet Hastanesi acil servisinde çalışmamızın yapıldığı zaman aralığında acil servisde nöbetçi acil servis uzmanı 24 saat esasına göre çalışmaktaydı. Kırık tanısı ve erken dönem tedavisi acil servis uzmanlığı çekirdek eğitim programında bulunmaktadır[16-18] Yatış gerektirmeyen olduğu pozisyonda alçı-atel ile tespit edilecek kırıklara acil uzmanın müdahale ettiği ve bunun \%12,8'lik bir oranı oluşturduğu görülmüştür.

Kırık hastalarının \%71,8 oranla ortopedi servisine yattığı görülmektedir. Vücut yüzey alanı düşünüldüğünde ortopedi tüm lokomotor sistem travmasının tanı ve tedavisini üstlenen bölüm olması sebebiyle en yüksek yatış oranına sahiptir[19,20]. Ancak hasta bir bütün olarak değerlendirilmelidir. Travmanın vücuttaki sistemik etkileri sıvı-elektrolit dengesi, renal fonksiyonların takibi ve diğer sistemler tek bir bölgeye odaklanılarak göz ardı edilmemelidir[21] Çalışmamızda genel cerrahi servisinde takip edilen hastaların bir kısmının pelvis kırığı olduğu görülmüştür. Batın içi organ patolojilerin takibi amacıyla genel cerrahi servisi tarafından takip edilmişlerdir.

Düşük enerjili travmalar toplumda daha sık görülmektedir[22]. Buna bağlı olarak da en sık görülen kırık bölgelerinden olan radius-ulna kırıkları ile tüm yaş gruplarında sıklıkla karışılaşılmaktadır[23]. Düşük enerjili travmalarla oluşan pelvis ve femur kırıkları daha çok geriatrik popülasyonda görülmektedir[24,25]. Çalışmamız kırık oluş mekanizmasına göre incelendiğinde en yüksek oranı düşmeye bağlı olan kırıklar oluşturmaktadır ve mevcut literatür verileriyle uyumludur.

Ortopedi servisine yatırılan hastaların \%80,7'sine cerrahi tedavi uygulanması, günlük ortopedi pratiğinde yatış endikasyonu olan hastaların çoğunlukla cerrahi tedavi gerektirecek hastalardan oluştuğunu göstermektedir. Öte yandan konservatif tedavi uygulanan hastaların \%50,7' kapalı redüksiyon ve alçı-atel uygulaması yapılmıştır ve çoğunlukla ayaktan kompartman takibi yapılmak üzere poliklinik takipleri yapılmaktadır. Yatış süreleri kıyaslandığında da cerrahi yapılan hastaların maruz kaldığı travma daha yüksek enerjili olup, ağrı, kanama miktarı, yara yerine pansuman gerekliliği gibi etkenlerle yatış sürelerinin daha uzun olduğu görülmüştür.

Sonuç olarak acil serviste kırık tanısı alan hastaların önemli bir kısmının, ortopedi kliniğince değerlendirildiği ve bunlarında önemli bir kısmının güncel ortopedik literatüre göre cerrahi olarak tedavi edildiği akılda tutulmalı ve tanı koyulduğunda ortopedi kliniğinden görüş alınmasını önermekteyiz.

\section{Çıkar çatışması / finansal destek beyanı}

Bu yazıdaki hiçbir yazarın herhangi bir çıkar çatışması yoktur. Yazının herhangi bir finansal desteği yoktur

\section{Kaynaklar}

1. Ege R. Travmatoloji. 5. Baskı. Ankara, Bizim Büro Basımevi; 2002.

2. Öztemur Z, Perçin S, Cilli K, Birinci Z. Evaluation of all bone fractures and/or joint dislocations at Emergency Department. Presented at XXII. SICOT/SIROT Triennial World Congress, San Diego USA, 2002.

3. Hopewell S, Adedire O, Copsey BJ, Boniface GJ, Sherrington C, Clemson L, Close JC, Lamb SE. Multifactorial and multiple component interventions for preventing falls in older people living in the community. Cochrane Database Syst Rev 2018; 7: 012221.

4. Wang H, Liu H, Wu J, Li C, Zhou Y, Liu J, Ou L, Xiang L. Age, gender, and etiology differences of sports-related fractures in children and adolescents: A retrospective observational study. Medicine (Baltimore) 2019; 98: 13961.

5. Aoki M, Abe T, Saitoh D, Oshima K.Epidemiology, Patterns of treatment, and Mortality of Pediatric Trauma Patients in Japan 2019; 9: 917.

6. Abegaz T, Gebremedhin S Magnitude of road traffic accident related injuries and fatalities in Ethiopia. PLoS One 2019; 14: 202240.

7. Meyyappan A, Subramani P, Kaliamoorthy S. A Comparative Data Analysis of 1835 Road Traffic Accident Victims. S. Ann Maxillofac Surg 2018; 8: 214-17. 
8. Montague MD, Lewis JT, Moushmoush O, Ryu J. Distal Radius Fractures: Does Obesity Affect Fracture Pattern, Treatment, and Functional Outcomes? Hand (N Y) 2018; 1: 15

9. Gürkany DY, Sönmez E , Korkmaz M . "Bir Üniversite Hastanesi Ortopedi Ve Travmatoloji Polikliniğine Başvuran Adli Olguların İncelenmesi. Bozok Tıp Dergisi 2018; 8: 3

10. Schermann H, Kadar A, Dolkart O, Atlan F, Rosenblatt $\mathrm{Y}$, Pritsch T.Repeated closed reduction attempts of distal radius fractures in the emergency department.Arch Orthop Trauma Surg 2018 138: 591-96.

11. Türkmen N, Akgöz S, Çoltu A, Ergin N. Uludağ Üniversitesi Tıp Fakültesi Acil Servisine başvuran adli olguların değerlendirilmesi. Uludağ Üniversitesi Tıp Fakültesi Dergisi 2005; 31: 25-29.

12. Ceylan S, Tümerdem N, Yaşar M, Kılıç S, Güleç M. GATA Eğitim Hastanesi İlk ve Acil yardım merkezine başvuran hastalardan yatırılarak tedavi edilenlerin ve hastalıklarının bazı özelliklerinin belirlenmesi. GATA Eğitim Hastanesi Dergisi 2000; 7: 23-27.

13. Avcı S, Erdoğdu Hi. Acil Servise Başvuran Geriatrik Hastaların Cinsiyete Göre Değerlendirilmesi.Kafkas Tıp Bilimleri Dergisi 2017; 7: 209-13

14. Şemin S, Güldal D. Acil servislere başvuran hastaların retrospektif analizi ve acil servislere yoğun başvuruların nedenleri. Toplum ve Hekim 1993; 58: 11-14.

15. Vanpee D, Swine C, Vandenbossche P, Gillet JB. Epidemiological profile of geriatric patients admitted to Emergency Department of a University Hospital localized in a rural area. Eur J Emerg Med 2001; 8: 301-304.

16. Brunett PH, Cameron PA. Trauma. In Tintinalli JE, Stapczynski JS, Ma OJ, Cline DM, Cydulka RK, Meckler GD, editors. Tintinalli's Emergency Medicine A comprehensive study guide. 7th ed. New York: Mc Graw Hill, 2011; 1671-76.
17. Yıldız M, Bozdemir MN, Kılıcaslan I, et al. The elderly trauma: a university emergency department experience of a universityaffiliated emergency department. Eur Rev Med Phalmacol Sci 20012; 16: 62-67.

18. Tıpta uzmanlık kurulu müfredat oluşturma ve standart belirleme sistemi. Acil tıp çekirdek eğitim müfredatı 2017:12-13

19. Akoğlu H, Denizbaşı $A$, Ünlüer $E$ ve ark. Marmara Üniversitesi Hastanesi Acil Servisine Başvuran Travma Hastalarının Demografik Özellikleri. Marmara Medical Journal 2005; 18: 113-22.

20. Durdu T, Kavalcı C, Yılmaz F et al. Analysis of Trauma Cases Admitted to the Emergency Department. Journal of Clinical and Analytical Medicine 2012; 1: 1-4

21. Long AM, Lefebvre CM, Masneri DA, Mowery NT, Chang MC, Johnson JE et.al. The Golden Opportunity: Multidisciplinary Simulation Training Improves TraumaTeam Efficiency. J Surg Educ 2019; 7204: 30740-42.

22. Báča $\mathrm{V}$, Klimeš J, Tolar $\mathrm{V}$, et al. A 1-year prospective monocentric study of limb, spinal and pelvic fractures: Can monitoring fracture epidemiology impact injury prevention programmes? Cent Eur J Public Health 2018; 26: 298-304.

23. Li SL, Li A, Cui P, Zhang YZ, Zhonghua Yi. Epidemic characteristics of adult Barton's fractures between Western and Eastern of China from 2010 to 2011. 2019; 99: 62-66.

24. Hayashi S, Noda T, Kubo S et al. Variation in fracture risk by season and weather: A comprehensive analysis across age and fracture site using a National Database of Health Insurance Claims in Japan. Bone 2019; 120: 512-18.

25. Court-Brown CM, Duckworth AD, Clement ND, McQueen MM. Fractures in older adults. A view of the future? Injury 2018; 49: 2161-66. 